\title{
El precio de luchar contra la COVID-19
}

\section{Ana Casaux-Huertas}

Escuela de Enfermería Fundación Jiménez Díaz. Campus Villalba. Fundación Renal Íñigo Álvarez de Toledo. Madrid. España

Como citar este artículo: Casaux-Huertas A. El precio de luchar contra la COVID-19. Enferm Nefrol. 2021 Abr-Jun;24(2):113-5

Miedo, incertidumbre, desconocimiento, falta de medios, enfermedad, sufrimiento, aislamiento, hospitales desbordados, personas padeciendo y muriendo solas. Un desafío mundial protagonizado por un virus de elevada transmisibilidad (coronavirus SARS-CoV-2) al que nunca antes nos habíamos enfrentado y que ha trastocado la vida de todo el orbe, una de las peores crisis de salud de nuestro tiempo.

Cabe reflexionar sobre cómo afrontar una pandemia siendo profesionales de la salud, sin sentir miedo a ser contagiados 0 a contagiar a nuestro entorno más directo (familiares, amigos, compañeros), a las situaciones críticas, al sufrimiento o a la muerte. Nuestra profesión lleva implícito un riesgo que en ocasiones puede resultar muy costoso para nuestra salud. A pesar de ello y ante condiciones tan adversas, los sanitarios hemos demostrado coraje, templanza, fuerza y valentía, estando a la cabeza de la respuesta a la COVID-19. Tras más de un año de lucha las cifras hablan por sí solas, hemos pagado un precio muy alto.

Debemos evidenciar la importancia que tienen las profesiones sanitarias en nuestra sociedad. En ellas recae la responsabilidad del cuidado tanto de la enfermedad como de la salud de la población y, en momentos como el actual, el papel de las profesiones sanitarias se vuelve fundamental e imprescindible. En situación de pandemia los profesionales de la salud nos volvemos aún más importantes si cabe, para el correcto funcionamiento del Sistema Sanitario y de la sociedad, pero no por ello estamos exentos del riesgo de contagio que tiene cualquier individuo que no pertenezca al sector sanitario.

Desde que el 31 de enero de 2020 se registrara el primer caso de COVID-19 en nuestro país, se han notificado alrededor de 131.313 casos confirmados de sanitarios infectados por el virus, lo cual supone aproximadamente el 3,6\% de los casos totales de C0VID-19 notificados a la Red Nacional de Vigilancia Epidemiológica (RENAVE)1. Según datos del último informe oficial del Ministerio de Sanidad ${ }^{1}$ las comunidades autónomas que han tenido un mayor número de sanitarios contagiados son la Comunidad Valenciana y Andalucía con 12.518 y 10.995 profesionales sanitarios infectados respectivamente, de los que conviene señalar que el $76,5 \%$ de los casos corresponde a mujeres con una media de edad de 46 años. Un 10,5\% del total de contagiados ha precisado hospitalización y de ellos el $1,1 \%$ lo ha hecho en una Unidad de Cuidados Intensivos (UCI). Un 0,1\% $(n=52)$ de los sanitarios infectados, ha fallecido a causa de la enfermedad ${ }^{1}$.

A nivel mundial, las últimas cifras de la Organización Mundial de la Salud (OMS) hablan de 4 millones de contagios entre los profesionales sanitarios, lo que supone un $14 \%$ de los casos globales de COVID-192, en el momento de redactarse esta editorial.

Estas alarmantes cifras ponen en tela de juicio las medidas preventivas que se utilizaron durante la primera fase de la pandemia y sacan a la luz la falta de protección que hemos sufrido los profesionales en el ejercicio de nuestras funciones, lo cual conlleva implicaciones más profundas en el control de la pandemia; cuando los profesionales no están adecuadamente protegidos, los cuidados de salud no pueden ser completamente eficaces.

Respecto a las medidas de protección y según los resultados de uno de los estudios del proyecto SANICOVI ${ }^{3}$, los profesionales sanitarios refieren una alta percepción de disponibilidad durante las primeras semanas de los equipos de protección personal (EPP) básicos (mascarillas FPPl y guantes) así como de los recursos 
disponibles para la higiene de manos. Muy al contrario, sucede con los EPP como las mascarillas FPP2 y FPP3, gafas y equipos de protección individual (EPI) completos, donde los profesionales refieren haber notado una carencia importante de los mismos ${ }^{3}$.

Las condiciones sanitarias y laborales del colectivo sanitario durante la pandemia han carecido de las adecuadas medidas de seguridad y de protección, tal y como han recogido las numerosas demandas que se han interpuesto contra las Comunidades Autónomas o el Gobierno.

Los gobiernos tienen la responsabilidad jurídica y moral de garantizar la salud, la seguridad y el bienestar de los trabajadores de la salud según lo recogido en la Carta de Seguridad de los Trabajadores de la salud de la OMS, donde una de las medidas registradas es la de "proteger a los trabajadores de la salud frente a los peligros físicos y biológicos". En ella se refleja que las autoridades competentes deberían entre otras ${ }^{2}$ :

- Garantizar la disponibilidad de EPP en todo momento, según sea pertinente con arreglo a las funciones y tareas que se realicen, en cantidades y tallas adecuadas y con una calidad aceptable.

- Velar para que se proporcione una capacitación adecuada sobre el uso apropiado del EPP y las precauciones de seguridad.

- Garantizar la vacunación de todos los trabajadores de la salud en situación de riesgo contra todas las infecciones prevenibles mediante vacunación [...] $y$ en el contexto de la respuesta de emergencia, garantizar el acceso prioritario de los trabajadores de la salud a las vacunas apenas se autoricen y distribuyan.

A día de hoy, una gran parte de estas medidas se están llevando a cabo de forma adecuada, lo cual ha favorecido la disminución en el número de contagios entre los sanitarios. No sucedió lo mismo al inicio de la pandemia, cuando las cifras de contagio se dispararon debido a la precariedad de la situación, a las carencias de un sistema sanitario que llegó en unas condiciones mermadas por las políticas de austeridad de la última década, a la falta de EPP y, por supuesto, al desconocimiento del mecanismo de transmisión de la enfermedad. Tanto es así, que a fecha 30 de abril de 2020 España estaba considerado uno de los países con mayor cifra de profesionales sanitarios contagiados del mundo, con el $21,4 \%$ de casos confirmados en este sector ${ }^{4}$. La situación era tal que los sanitarios españoles llegamos a ser definidos como "kamikazes" por el diario estadounidense "The New York Times"

Muchos de nosotros nos aislamos voluntariamente para preservar la salud de nuestros seres queridos, alterando de forma drástica nuestras vidas; otros, desgraciadamente, fueron apartados y estigmatizados por la sociedad debido al miedo que provoca el contagio.

El colectivo sanitario se ha visto obligado a asumir riesgos innecesarios por falta de medidas adecuadas de protección que han puesto en riesgo no sólo a los profesionales sino también a los pacientes, a otros trabajadores y a sus familiares. Una situación así no debe volver a producirse.

Muchos son los compañeros que han enfermado y por suerte han conseguido superar la enfermedad, pero son también muchos los que aún continúan con secuelas y a muchos otros desgraciadamente ya no los tenemos aquí. A todos quiero expresarles nuestro más profundo agradecimiento y reconocimiento por su incansable labor, por su gran profesionalidad, por su valentía y su entereza ante la adversidad, recordando especialmente a todos y cada uno de los que han perdido en esta pandemia lo más valioso, la vida.

\section{Bibliografía}

1. Centro de Coordinación de Alertas y Emergencias Sanitarias. Actualización $n^{\circ}$ 375. Enfermedad por el coronavirus (COVID-19). [consultado 14 may 2021]. Madrid: Ministerio de Sanidad. Gobierno de España. Disponible en: https://www.mscbs.gob.es/profesionales/saludPublica/ccayes/alertasActual/nCov/documentos/Actualizacion_375_COVID-19.pdf.

2. OMS: Garantizar la seguridad de los trabajadores de la salud para preservar la de los pacientes. Organización Mundial de la Salud [Internet] 2020 [consultado 18 may 2021]; [aprox 5 pantallas]. Disponible en: https://www.who.int/es/news/item/17-09-2020keep-health-workers-safe-to-keep-patients-safewho.

3. Moreno-Casbas MT. Factores relacionados con el contagio por SARS-CoV-2 en profesionales 
de la salud en España. Proyecto SANICOVI. Enferm Clin. 2020 [consultado 18 may 2021]. OctDic;17(4):251-60. Disponible en: https://www. ncbi.nlm.nih.gov/pmc/articles/PMC7247504/pdf/ main.pdf.

4. Red Nacional de Vigilancia Epidemiológica. Informe sobre la situación de COVID-19 en España Informe COVID-19 $n^{\circ}$ 27. Instituto de Salud Carlos III. Madrid. 30 de abril de 2020 [consultado 18 may 2021]. Disponible en: https://www.isciii.es/QueHacemos/Servicios/VigilanciaSaludPublicaRENAVE/ EnfermedadesTransmisibles/Documents/INFORMES/Informes\%20C0VID-19/Informe\%20n\%C2\%BA\%2027.\%20Situaci\%C3\%B3n\%20 de $\% 20$ COVID-19\%20en\%20Espa\%C3\%Bla\%20 a\%2030\%20de\%20abril\%20de\%202020.pdf.

5. The New York Times. New York [consultado $25 \mathrm{abr}$ 2021]. Disponible en: https://www.nytimes.com/ video/world/europe/100000007051789/coronavirus-ppe-shortage-health-care-workers.html.

Este artículo se distribuye bajo una Licencia Creative Commons Atribución-NoComercial 4.0 Internacional. https://creativecommons.org/licenses/by-nc/4.0/

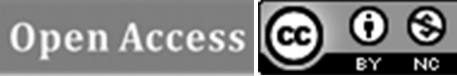

